\title{
OPEN Construction of an artificial system for ambrein biosynthesis and investigation of some biological activities of ambrein
}

Yota Yamabe ${ }^{1,4}$, Yukina Kawagoe ${ }^{1,4}$, Kotone Okuno ${ }^{1}$, Mao Inoue ${ }^{1}$, Kanako Chikaoka ${ }^{1}$ Daijiro Ueda ${ }^{1}$, Yuko Tajima ${ }^{2}$, Tadasu K. Yamada ${ }^{2}$, Yoshito Kakihara ${ }^{3 凶}$, Takashi Hara $^{1 \bowtie}$ \& Tsutomu Sato ${ }^{1 凶}$

Ambergris, a sperm whale metabolite, has long been used as a fragrance and traditional medication, but it is now rarely available. The odor components of ambergris result from the photooxidative degradation of the major component, ambrein. The pharmacological activities of ambergris have also been attributed to ambrein. However, efficient production of ambrein and odor compounds has not been achieved. Here, we constructed a system for the synthesis of ambrein and odor components. First, we created a new triterpene synthase, "ambrein synthase," for mass production of ambrein by redesigning a bacterial enzyme. The ambrein yields were approximately 20 times greater than those reported previously. Next, an efficient photooxidative conversion system from ambrein to a range of volatiles of ambergris was established. The yield of volatiles was 8-15\%. Finally, two biological activities, promotion of osteoclast differentiation and prevention of amyloid $\beta$-induced apoptosis, were discovered using the synthesized ambrein.

Ambergris, a metabolic product of the sperm whale (Physeter catodon or Physeter macrocephalus), accumulates as gut concretions with a probability of about $1 \%$, and is one of the most valuable scents of animal origin ${ }^{1-3}$. Ambergris, which exhibits various medicinal properties, has also been used worldwide as a traditional medication for maladies such as migraines, the common cold, constipation, disease of the nervous system, and rheumatism ${ }^{4-6}$. In addition, it is often used as an aphrodisiac ${ }^{7}$. However, ambergris is almost inaccessible because sperm whales are now protected under the Convention on the International Trade of Endangered Species of Wild Fauna and Flora. On rare occasions, jetsam ambergris is found on beaches around the world, and traded at a high price ${ }^{8}$. The odor components of ambergris result from the photooxidative degradation of the major component, ambrein

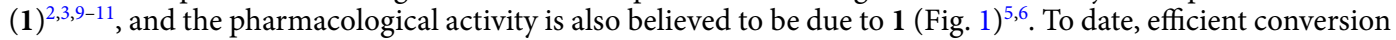
to both 1 and odor components (2-5, Fig. 1) has never been achieved. The reported yields of chemical synthesis of $\mathbf{1}$ and conversion of $\mathbf{1}$ to odor components are 1.3-3.8\% and approximately $1 \%$, respectively ${ }^{11-14}$. In addition, since the biosynthetic pathway of $\mathbf{1}$ in sperm whales remains unclear, it is not possible to utilize the biosynthetic enzyme that produces 1 .

Successful artificial enzymatic synthesis of $\mathbf{1}$ was reported in 2013 using onoceroid synthase, BmeTC, from Bacillus megaterium, which sequentially cyclizes both termini of squalene (6; Fig. 2a $)^{12}$. Presumably, BmeTC first cyclizes one side end of $\mathbf{6}$, converts it into a bicycle $\mathbf{7}$, and then incorporates 7 into the same active site as a substrate and cyclizes the remaining terminal to produce onoceroids 8 and $\mathbf{9}$ (Fig. 2a). BmeTC catalyzes this two-step reaction (acycle [6] $\rightarrow$ bicycle [7] $\rightarrow$ bicycle-bicycle [8 and 9]; Fig. 2a) ${ }^{15}$. BmeTC can successfully form $\mathbf{1}$ using an abnormal monocyclic product $(\mathbf{1 0})$, synthesized by a squalene-hopene cyclase variant $\left(\mathrm{SHC}^{\mathrm{D} 377 \mathrm{C}}\right)$, as a substrate (Fig. 2b $)^{15}$. Hence, enzymatic synthesis of $\mathbf{1}$ from inexpensive $\mathbf{6}$ was achieved via the route "acycle $\mathbf{6} \rightarrow$ monocycle $10 \rightarrow$ bicycle-monocycle 1" (Fig. $2 \mathrm{~b})^{15}$. Furthermore, the BmeTC variant BmeTC ${ }^{\mathrm{D} 73 \mathrm{C}}$, which is an equivalent point mutation as $\mathrm{SHC}^{\mathrm{D} 377 \mathrm{C}}$, could reportedly synthesize $\mathbf{1}$ from $\mathbf{6}$ both in vitro and in vivo (Fig. 2c) ${ }^{16-18}$. By

${ }^{1}$ Department of Agriculture, Faculty of Agriculture, and Graduate School of Science and Technology, Niigata University, 8050, Ikarashi-2, Nishi-ku, Niigata, Japan. ${ }^{2}$ Department of Zoology, National Museum of Nature and Science, 4-1-1Amakubo, Tsukuba, Ibaraki, Japan. ${ }^{3}$ Division of Dental Pharmacology, Department of Tissue Regeneration and Reconstruction, Faculty of Dentistry, Niigata University Graduate School of Medical and Dental Sciences, Chuo-ku, Niigata 951-8514, Japan. ${ }^{4}$ These authors contributed equally: Yota Yamabe and Yukina Kawagoe. ${ }^{\varpi}$ email: kakihara@dent.niigata-u.ac.jp; harata@agr.niigata-u.ac.jp; satot@agr.niigata-u.ac.jp 


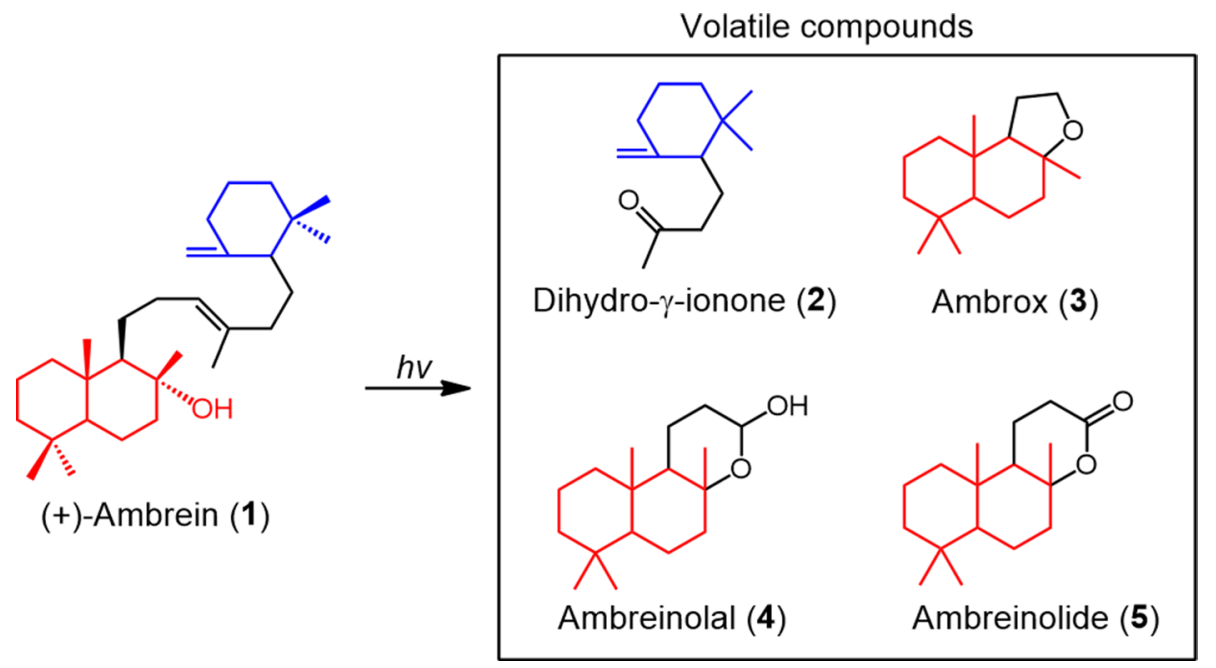

Figure 1. Photooxygenation of 1 to produce volatile compounds (2-5). Tricyclic triterpene, (+)-ambrein (1), is the primary source of ambergris-derived odor components ${ }^{2-4,9-11}$. Photooxidative degradation of $\mathbf{1}$ by ${ }^{1} \mathrm{O}_{2}$ around its central double bond produces volatile compounds with smaller molecular weights ${ }^{2-4,9-11} \cdot \mathbf{2 - 5}$ are the main components identified. Tricyclic volatiles 3-5 originate from the bicyclic part of $\mathbf{1}$, while the smaller fragment 2 is related to the monocyclic part of $\mathbf{1}^{2-4,9-11}$.

acquiring a "new route" that forms a monocycle 10, in addition to the wild-type route (WT route) that forms bicycle 7 , BmeTC ${ }^{\mathrm{D} 373 \mathrm{C}}$ synthesizes 1 via the two pathways, $\mathbf{6} \rightarrow \mathbf{7} \rightarrow \mathbf{1}$ (WT route $\rightarrow$ new route) and $\mathbf{6} \rightarrow \mathbf{1 0} \rightarrow \mathbf{1}$ (new route $\rightarrow$ WT route) (Fig. 2c). In a bioreactor, the production of $\mathbf{1}$ by BmeTC ${ }^{\mathrm{D} 373 \mathrm{C}}$ in yeast Pichia pastoris reached a maximum titer of $105 \mathrm{mg} \mathrm{L}^{-1}$ of culture medium ${ }^{17}$, which was higher than that produced using other host systems or with the two enzyme system involving SHC ${ }^{\mathrm{D} 377 \mathrm{C}}$ and BmeTC ${ }^{\mathrm{WT}}$ (Supplementary Table 1 ) $^{17-19}$.

Since the production efficiency of $\mathbf{1}$ and odor components was still too low for industrialization, we sought to construct an artificial synthesis system that is dramatically more efficient than the one used currently. First, we created an "ambrein (1) synthase" that produces a higher yield of $\mathbf{1}$ than that of the final products (8 and $\mathbf{9})$ produced by wild-type BmeTC. Next, we established an efficient photooxidative conversion system to transform 1 to volatile components of ambergris. Finally, the synthesized 1 was analyzed for its bioactivities that have not yet been explored, by using cell culture assays. In this study, we focused on the effects of $\mathbf{1}$ on bone cell differentiation and against amyloid $\beta$ neurotoxicity, since ambergris has been used in traditional medicine to treat rheumatism and disease of the nervous system.

\section{Results}

Screening for variants suitable for the synthesis of 1 . Mutation analysis of BmeTC and SHC suggested that the D373 mutation of BmeTC was important for the synthesis of $\mathbf{1}$. However, none of the studies have analyzed D373 variants other than BmeTC ${ }^{\mathrm{D} 373 \mathrm{C}}$. In this study, an Escherichia coli cell-free system expressing the D373 variants (Supplementary Fig. 1) substituted with 11 amino acids (C, A, F, G, H, L, M, N, Q, S and W) was used to confirm their ability to convert 6 to 1 . The results indicated that only the C mutant produced $\mathbf{1}(12.5 \%$ yield) (Fig. 3). This revealed that cysteine at position D373 is critical to form 1. BmeTC ${ }^{\mathrm{D} 373 \mathrm{C}}$ accumulated large amounts of intermediates, bicycle 7 and monocycle 10, during the reaction with 6 (Fig. 3), showing that the bulky bicyclic and monocyclic structures of intermediates (Fig. 4a) interfered in the second-step reaction.

Based on this working hypothesis, 6 residues (Y167, Y255, Y257, N302, L596, and F600) that were presumed to be located near the bicyclic or monocyclic structure during the second reaction were selected based on the modeling structure of BmeTC (Fig. 4) and replaced by a smaller Ala. Enzymatic reactions of 6 Ala mutants were performed using a cell-free system (Supplementary Fig. 1). Y167A, Y257A, and N302A variants showed a higher level of activity on substrates 6 and 7 to produce 8 and 9, compared with BmeTC ${ }^{\text {WT }}$ (Fig. 5a,b and Supplementary Figs. 2 and 3). Whereas the product of BmeTC ${ }^{\mathrm{Y} 167 \mathrm{~A}}$ containing a novel tricyclic compound was previously reported ${ }^{20}$, the enzyme activity was first revealed in this study.

On the other hand, the yield of $\mathbf{1}$ synthesized from $\mathbf{1 0}$ by the L596A variant was 8 times that synthesized by BmeTC $^{\text {WT }}$ (Fig. 5c and Supplementary Fig. 4). Thus, it may be useful to replace BmeTC ${ }^{\text {WT }}$ with BmeTC B $^{\text {L596A }}$ during the second step of the two-enzyme system consisting of SHC ${ }^{\mathrm{D} 37 \mathrm{C}}$ and BmeTC ${ }^{\mathrm{WT}}$ (Fig. 2b). However, as the single enzyme system of BmeTC ${ }^{\mathrm{D} 373 \mathrm{C}}$ has been shown to be more advantageous for producing of 1 in yeast (Supplementary Table 1$)^{17,18}$, the present study further improved upon BmeTC ${ }^{\mathrm{D} 373 \mathrm{C}}$.

Construction of the system for artificial biosynthesis of $1 . \quad$ In order to improve its reactivity with monocyclic 10 and bicyclic substrate 7, 4 mutations (Y167A, Y257A, N302A, and L596A) were introduced into BmeTC $^{\mathrm{D} 373 \mathrm{C}}$, following which the reactivity of these variants (Y167A/D373C, Y257A/D373C, N302A/D373C, and D373C/L596A) with 3 substrates (6, 7, and 10) was accurately analyzed using the purified enzyme (Fig. 6, Supplementary Figs. 5 and 6). The results indicated that of the double mutants, only BmeTC ${ }^{\mathrm{Y} 167 \mathrm{~A} / \mathrm{D} 373 \mathrm{C}}$ produced 
a

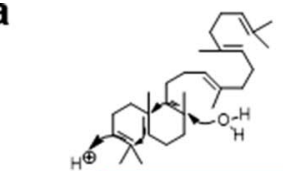

Squalene (6)

1st Reaction $\downarrow$ Bme TC $^{\mathrm{WT}}$

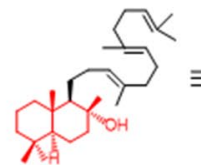

Bicycle (7)

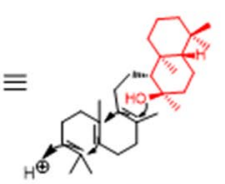

Bicycle (7)

2nd Reaction $\downarrow$ Bme TC $^{\text {WT }}$

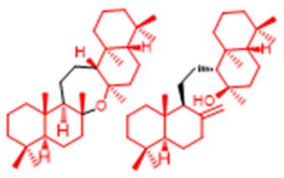

Bicycle-Bicycle

Onoceroids ( 8 and $\mathbf{9}$ ). c

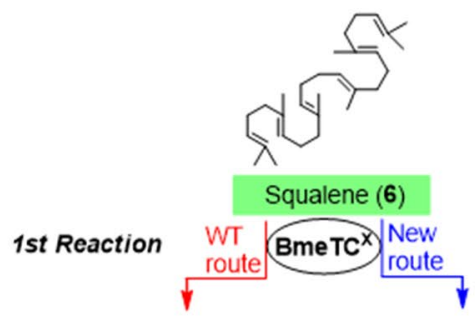<smiles>CC(C)(Cc1ccccc1)CC1CCCCC1</smiles>

\section{2nd Reaction \\ Bicycle (7)

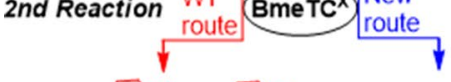

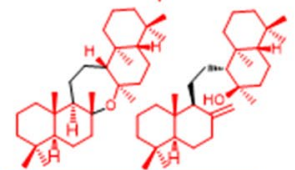

Bicycle-Bicycle Onoceroids (8 and $\mathbf{9}$ )

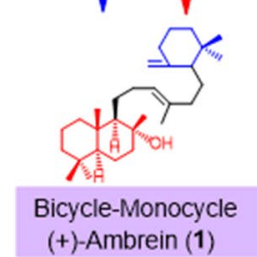

b
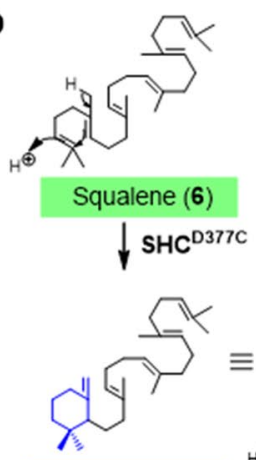

Monocycle (10)

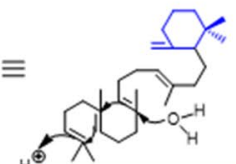

Monocycle (10)

$\downarrow$ BmetcWT

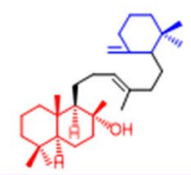

Bicycle-Monocycle (+)-Ambrein (1)

Figure 2. The enzymatic reaction pathway described in this study. (a) Mechanism of conversion of $\mathbf{6}$ to 8 and $\mathbf{9}$ by BmeTC ${ }^{\mathrm{WT}}$. (b) Mechanism of conversion of $\mathbf{6}$ to $\mathbf{1}$ by SHC ${ }^{\mathrm{D} 37 \mathrm{C}}$ and $\mathrm{BmeTC}^{\mathrm{WT}}$. (c) Reaction pathway by $\mathrm{BmeTC}^{\mathrm{D} 373 \mathrm{C}}$ or BmeTC ${ }^{\mathrm{Y} 167 \mathrm{~A} / \mathrm{D} 373 \mathrm{C}}$. BmeTC $\mathrm{B}^{\mathrm{D} 33 \mathrm{C}}$ or BmeTC ${ }^{\mathrm{Y} 167 \mathrm{~A} / \mathrm{D} 373 \mathrm{C}}$ form final products $(\mathbf{1}, \mathbf{8}, \mathbf{9}$ and 11) through a two-step reaction from 6 via intermediates (7 and 10) and may have catalytic functions in two pathways (WT and New route). (d) Two enzyme system (BmeTC ${ }^{\mathrm{WT}}$ and $\mathrm{BmeTC}^{\mathrm{Y} 167 \mathrm{~A} / \mathrm{D} 373 \mathrm{C}}$ ) constructed in this study.

$\mathbf{1}$ from 6, in which the yield of $\mathbf{1}(21.5 \%)$ was improved approximately tenfold over that of BmeTC ${ }^{\mathrm{D} 373 \mathrm{C}}(2.2 \%)$ (Fig. 6a). If BmeTC ${ }^{\mathrm{Y} 167 \mathrm{~A} / \mathrm{D} 373 \mathrm{C}}$ produces 1 in P. pastoris with the same efficacy as BmeTC ${ }^{\mathrm{D} 373 \mathrm{C} 17}$, an end yield of approximately $1 \mathrm{~g} 1$ / L culture medium can be expected.

The conversion of 6 and 7 by BmeTC $\mathrm{Y}^{\mathrm{Y} 167 \mathrm{~A} / \mathrm{D} 373 \mathrm{C}}$ to yield $\mathbf{1}$ (21.5 and $62.0 \%$, respectively) were 4.7 and 7.2 times greater than the conversion of 6 and 7 by BmeTC ${ }^{\mathrm{WT}}$ to 8 and 9 ( 4.6 and $8.6 \%$, respectively) by BmeTC ${ }^{\mathrm{WT}}$ (Fig. 6a,b). This indicated that the double mutant enzyme displayed activity beyond its original function to form onoceroids (8 and 9). Since the activity of previously constructed BmeTC ${ }^{\mathrm{D} 373 \mathrm{C}}$ on substrates $\mathbf{6}$ and 7 (producing 2.2 and $0 \%$ of 1 , respectively) was lower than that of BmeTC ${ }^{\text {WT }}$ (Fig. 6a,b), we named the novel enzyme created in this study, BmeTC ${ }^{\mathrm{Y} 167 \mathrm{~A} / \mathrm{D} 373 \mathrm{C}}$, as "ambrein synthase." 


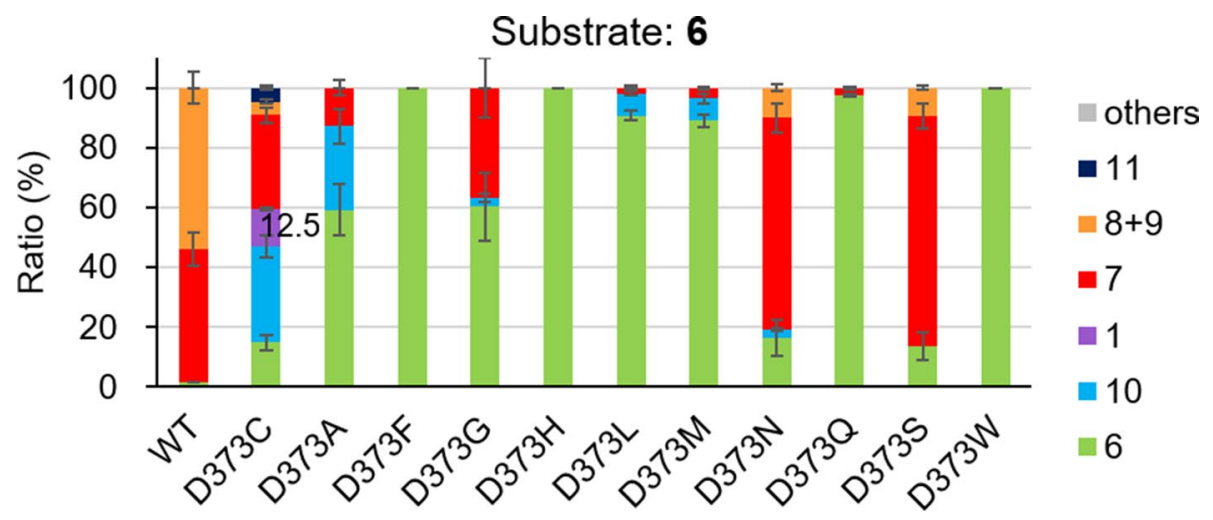

Figure 3. Yield of products produced by BmeTC ${ }^{\mathrm{X}}$ from substrate 6 in a cell-free system.

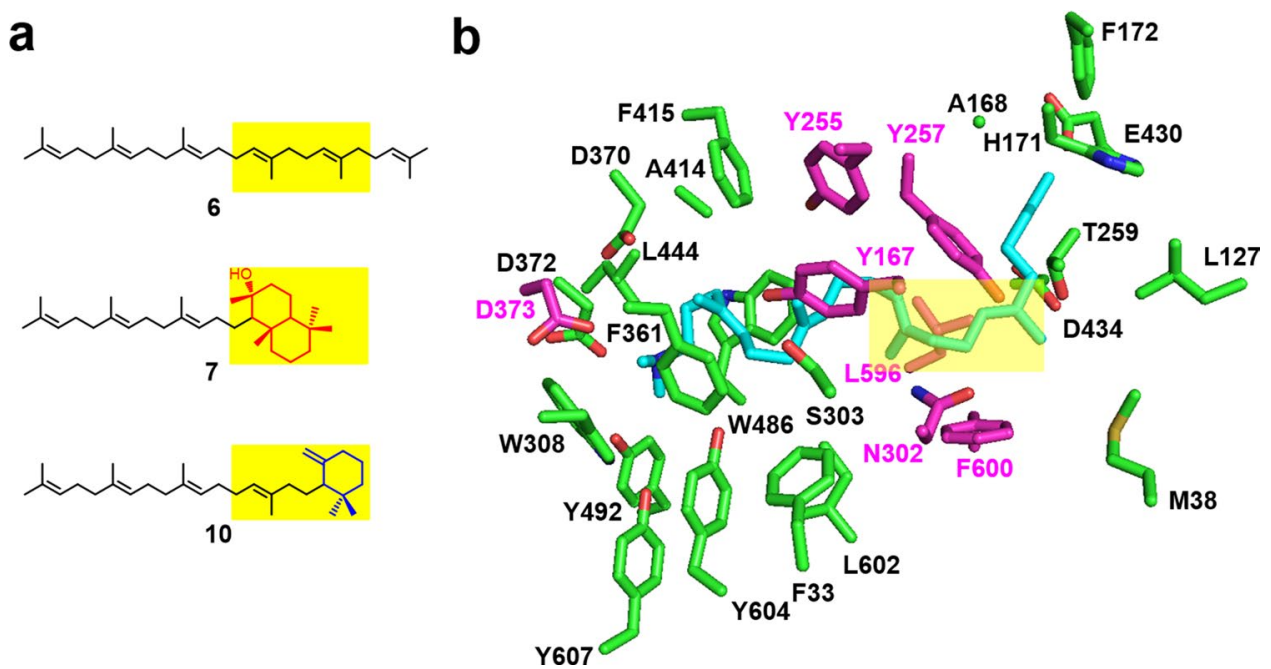

Figure 4. Selection of residues, presumably located near a bicyclic or monocyclic structure, during the second step of the reaction. (a) Structures of substrates 6, 7, and 10. Positions corresponding to bicyclic or monocyclic structure on the substrates are shown in yellow. (b) Homology model of BmeTC. The 3D structure of BmeTC was modeled using SWISS-MODEL. The structure was constructed using the coordinates of SHC complexed with 2-azasqualene inhibitor [Protein Data Bank (PDB) code: 1UMP] as a template and displayed using PYMOL. Blue: 2-azasqualene; pink and green: residues within $4 \AA$ of 2 -azasqualene; pink: residues targeted in this study; yellow: positions corresponding to bicyclic or monocyclic structure on the substrates.

$\mathrm{BmeTC}^{\mathrm{Y} 167 \mathrm{~A} / \mathrm{D} 373 \mathrm{C}}$ reacted best with 7 rather than $\mathbf{6}$ (Fig. 6a,b), indicating that the reaction with 6 was slower in the first step $(\mathbf{6} \rightarrow 7)$ than in the second step $(7 \rightarrow \mathbf{1})$ (Fig. $2 \mathrm{c})$; thus, the first step would be rate limiting. In addition, BmeTC ${ }^{\mathrm{Y} 167 \mathrm{~A} / \mathrm{D} 373 \mathrm{C}}$ did not react with 10 (Fig. 6c), suggesting that 1 was specifically synthesized from $\mathbf{7}$ when $\mathbf{6}$ was used as a substrate, and that $\mathrm{BmeTC} \mathrm{Y}^{\mathrm{Y} 167 \mathrm{~A} / \mathrm{D} 373 \mathrm{C}}$ mainly catalyzed the reaction $\mathbf{6} \rightarrow \mathbf{7} \rightarrow \mathbf{1}$ (Fig. 2c). Hence, to accelerate the reaction in the first step of $6 \rightarrow 7 \rightarrow \mathbf{1}$ and reduce the overall quantity of by-product $\mathbf{1 0}$, $\mathbf{6}$ was converted to $\mathbf{1}$ by adding BmeTC ${ }^{\mathrm{WT}}$ to the reaction solution of BmeTC $\mathrm{B}^{\mathrm{Y} 167 \mathrm{~A} / \mathrm{D} 373 \mathrm{C}}$ (Fig. 2d). The yield of 1 was evaluated via a system, in which the total amount of enzymes BmeTC ${ }^{\mathrm{WT}}$ and BmeTC ${ }^{\mathrm{Y} 167 \mathrm{~A} / \mathrm{D} 373 \mathrm{C}}$ was the same as that of a single enzyme. The yield of $\mathbf{1}(46.0 \%)$ obtained via the new system, comprising BmeTC ${ }^{\mathrm{WT}}$ and $\mathrm{BmeTC}^{\mathrm{Y} 167 \mathrm{~A} / \mathrm{D} 373 \mathrm{C}}$ was approximately twice that obtained via BmeTC ${ }^{\mathrm{Y} 167 \mathrm{~A} / \mathrm{D} 373 \mathrm{C}}$ alone $(21.5 \%)$ and approximately 20 times that of BmeTC ${ }^{\mathrm{D} 373 \mathrm{C}}(2.2 \%)$ (Fig. 6a). Since the 2 enzymes can be co-expressed in the yeast P. pastoris ${ }^{17}$, the new system should be applicable in vivo (calculated titer: approximately $2 \mathrm{~g} 1 / \mathrm{L}$ culture medium in the bioreactor).

Conversion of synthetic 1 into volatile components. Enzymatically synthesized 1 was converted to volatiles by ${ }^{1} \mathrm{O}_{2}$, and these volatiles were compared with the volatiles present in ambergris. Ethanol tinctures of two ambergris samples (Supplementary Fig. 7) mainly contain 4 known compounds (2-5) and 6 other unknown compounds (12-17) (Fig. 7a,b). The ratio of volatile components was slightly different between the two ambergris samples obtained by us (Fig. 7b), suggesting that the slight difference between their odors could be due to differences in the oxidizing conditions of $\mathbf{1}$ in the environment. The conversion of $\mathbf{1}$ to volatile compounds was conducted via UV or visible light treatment using 3 photosensitizers (rose Bengal: RB, 5,10,15,20-tetraphenyl- 

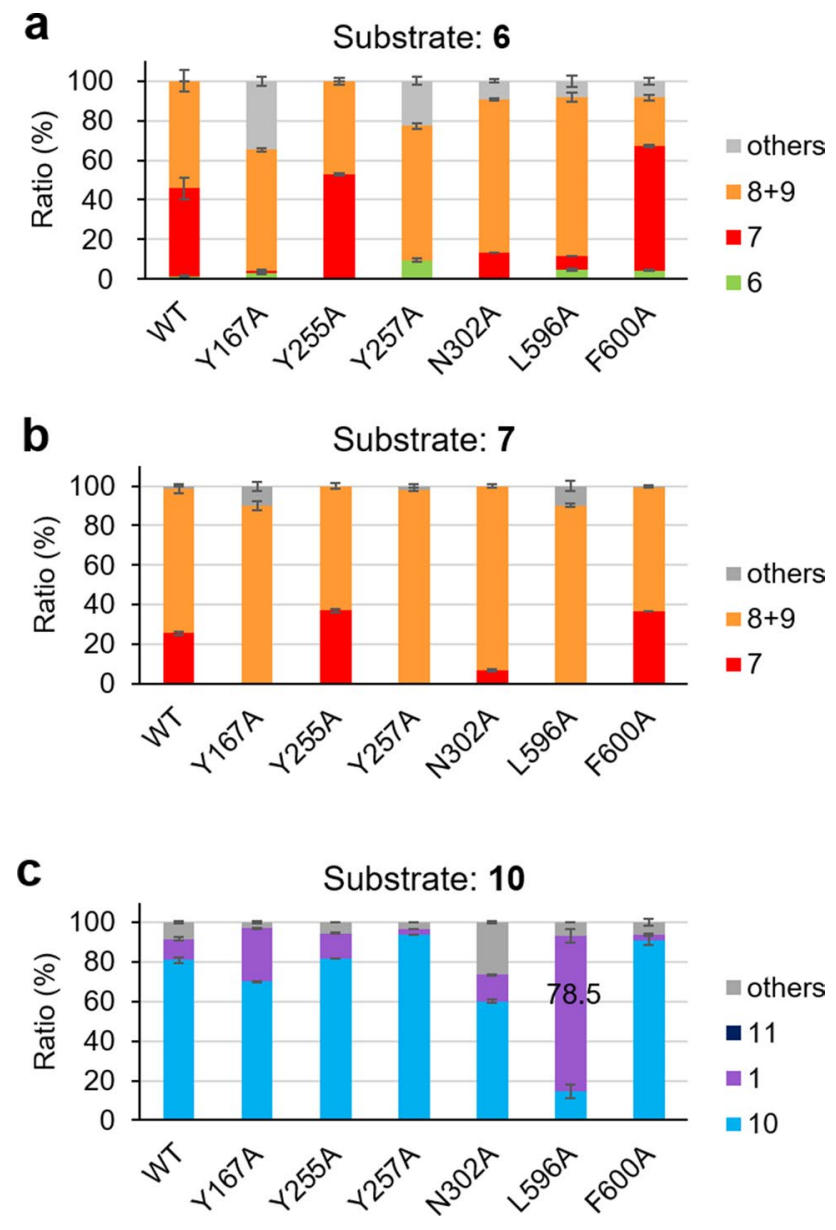

Figure 5. Yield of products produced by $\operatorname{BmeTC}^{\mathrm{X}}$ from substrates $(\mathbf{6}, 7$, and 10$)$ in a cell-free system.

porphine: TPP, and methylene blue: MB). Volatile components similar to that of ambergris (2-5 and 12-17) were detected (Fig. 7b and Supplementary Figs. 8-12).

The yield of volatile components (ca. 1\%) and the residual rate of 1 (ca.68\%) obtained from synthetic 1 via UV treatment were similar to those of ambergris ( $c a .1 \%$ and $c a .68 \%$, respectively) (Fig. $7 \mathrm{c}$, d), and also similar to previously reported results obtained by the conversion of 1 to volatile components via visible light using a photosensitizer 5,10,15,20-tetraphenyl-21H, $23 \mathrm{H}$-porphine copper (II) (yield: $c a$. $1 \%$ and residual rate: $c a .50 \%)^{11}$. In the current study, visible light treatment using 3 photosensitizers (RB, TPP and MB) resulted in higher yields of volatile components (ca. 8-15\%) and a lower retention of $1(c a .0-13 \%)$ (Fig. 7c,d). The formation rates of volatiles from UV and RB treated 1 were more similar to those of ambergris, while the TPP and MB treated samples had a much higher proportion of $\mathbf{1 4}(12.2 \%)$ and $\mathbf{3}(25.5 \%)$, respectively, than the ethanol tinctures of two ambergris samples (1.2-2.1\% and 1.2-4.2\%) (Fig. 7b). After wetting samples with filter papers and evaporating the solvent, we compared the scents and found that the scents associated with UV and RB treatments of 1 were similar to those obtained from the ethanol tinctures of two ambergris, whereas the scents associated with TPP and MB treatments were different. Notably, the yield of valuable fragrance compound $\mathbf{3}$, which is used as a substitute for ambergris samples ${ }^{1-4}$, was 6-21 times higher in MB treated 1 than that obtained from the ethanol tinctures of two ambergris (Fig. 7b). The artificial synthetic system for the major component $\mathbf{1}$ and odor components of ambergris achieved efficient enzymatic conversion of $\mathbf{6}$ to $\mathbf{1}$ as well as efficient conversion of $\mathbf{1}$ to volatile components by ${ }^{1} \mathrm{O}_{2}$.

Biological activity of 1 . Ambergris was previously used as a traditional medicine for various maladies ${ }^{4,7}$. However, the biological activities of natural 1, the main component of ambergris (ex. ambergris samples 1 and 2 contained 1 at $\mathrm{ca}$. 68\%; Fig. 7d) have not been assessed extensively due to its scarcity. To date, only its aphrodisiac, antinociceptive, and elastase release inhibitory activities are known ${ }^{5,6,21}$. Since the enzymatic synthesis in the current study enabled sufficient production of synthetic 1, its two biological activities were analyzed. First, we analyzed the effect of $\mathbf{1}$ on the differentiation of bone cells, osteoblasts and osteoclasts. Extracellular calcium deposited by mature osteoblasts was stained with alizarin red $\mathrm{S}$ after cells were incubated with or without $10 \mu \mathrm{M}$ 1. However, a significant effect of $\mathbf{1}$ on the osteoblastic activity was not detected (Supplementary Fig. 13). In contrast, 1 enhanced osteoclastic differentiation at a concentration of $10 \mu \mathrm{M}$ (Fig. 8). The results indicated that 
a

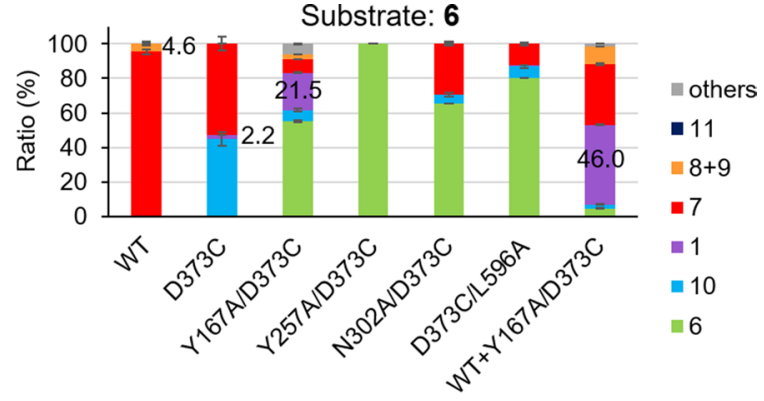

b

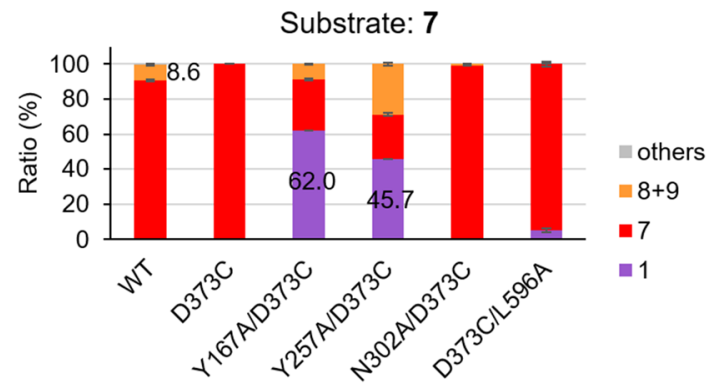

C

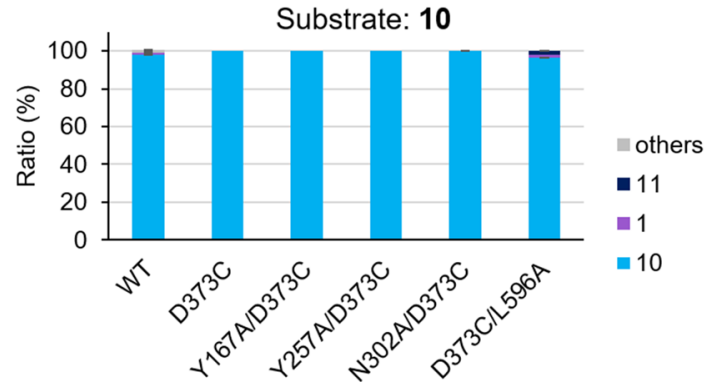

Figure 6. Yield of products produced by $\mathrm{BmeTC}^{\mathrm{X}}$ from substrates $(\mathbf{6}, 7$, and 10$)$ in the system using purified enzymes.

1 significantly increased the number of mature osteoclasts in a concentration-dependent manner (Fig. 8). The effect of $50 \mu \mathrm{M} 1$ was similar to that of $5 \mu \mathrm{M}$ kenpaullone $e^{22}$, which is a strong activator of osteoclastic differentiation. This result suggested that $\mathbf{1}$ may be a promising drug candidate for osteopetrosis, caused by defective osteoclast function.

Next, we analyzed the protective effect of 1 against amyloid $\beta(A \beta)$-mediated neurotoxicity. Alzheimer's disease (AD), the most common type of dementia, is an age-related progressive neurodegenerative disorder characterized by depositions of amyloid $\beta(\mathrm{A} \beta)$, the primary component of senile plaques ${ }^{23}$. $A \beta$ peptides elicit neurotoxicity, leading to neuronal loss and cognitive deficits. We examined the effect of 1 on A $\beta$-induced apoptotic cell death in human neuroblastoma SK-N-SH cells, in which $\mathrm{A} \beta_{1-42}$ was used to induce cell death. Exposure of SK-N-SH cells to $1 \mu \mathrm{M} \mathrm{A} \beta_{1-42}$ for $24 \mathrm{~h}$ led to a markedly increased percentage of early apoptotic cells $\left(A n n e x i n \mathrm{~V}^{+} / 7-\mathrm{AAD}^{-}\right)$, as well as late apoptotic and dead cells (Annexin $\mathrm{V}^{+} / 7-\mathrm{AAD}^{+}$, Fig. 9). A $\beta_{1-42}$-induced apoptosis was significantly inhibited by pretreatment with 1 at concentrations of $1-20 \mu \mathrm{M}$ for $24 \mathrm{~h}$ prior to $\mathrm{A} \beta_{1-42}$ exposure (Fig. 9). These results implied that $\mathbf{1}$ possesses the potential to prevent $\mathrm{A} \beta$ neurotoxicity. Presently, we are investigating whether $\mathbf{1}$ modulates apoptosis signaling pathways and comparing the efficacy of $\mathbf{1}$ and other Alzheimer's drug candidates targeting $A \beta$ neurotoxicity.

\section{Discussion}

The present study redesigned BmeTC to create a new enzyme named "ambrein (1) synthase" (BmeTC ${ }^{\mathrm{Y} 167 \mathrm{~A} / \mathrm{D} 373 \mathrm{C}}$ ), which displays activity beyond its wild-type function (production of $\mathbf{8}$ and $\mathbf{9}$ ). We also constructed an efficient in vitro artificial biosynthetic pathway, which can be used for mass production of 1 in vivo. The new two-enzyme system (Fig. 2d) gives approximately 20 times more yield of $\mathbf{1}$ than the most efficient system currently known $\left(\mathrm{BmeTC}^{\mathrm{D} 33 \mathrm{C}}\right)^{17}$ (Fig. $6 \mathrm{a}$ ) and is expected to produce $2 \mathrm{~g} \mathbf{1} / \mathrm{L}$ culture medium in yeast $P$. pastoris. Recently, it was hypothesized that $\mathbf{1}$ is biosynthesized via the pathway $\mathbf{6} \rightarrow \mathbf{7} \rightarrow \mathbf{1}$ in sperm whales ${ }^{24}$. In addition, 2 enzymes are utilized to convert symmetric compounds to asymmetric fern onoceroids and carotenoids ${ }^{25,26}$, via a strategy similar to the one we finally adopted. It is interesting that the pathways adopted by nature are similar to the artificial pathways (Fig. 2d) we have developed. 
a

b
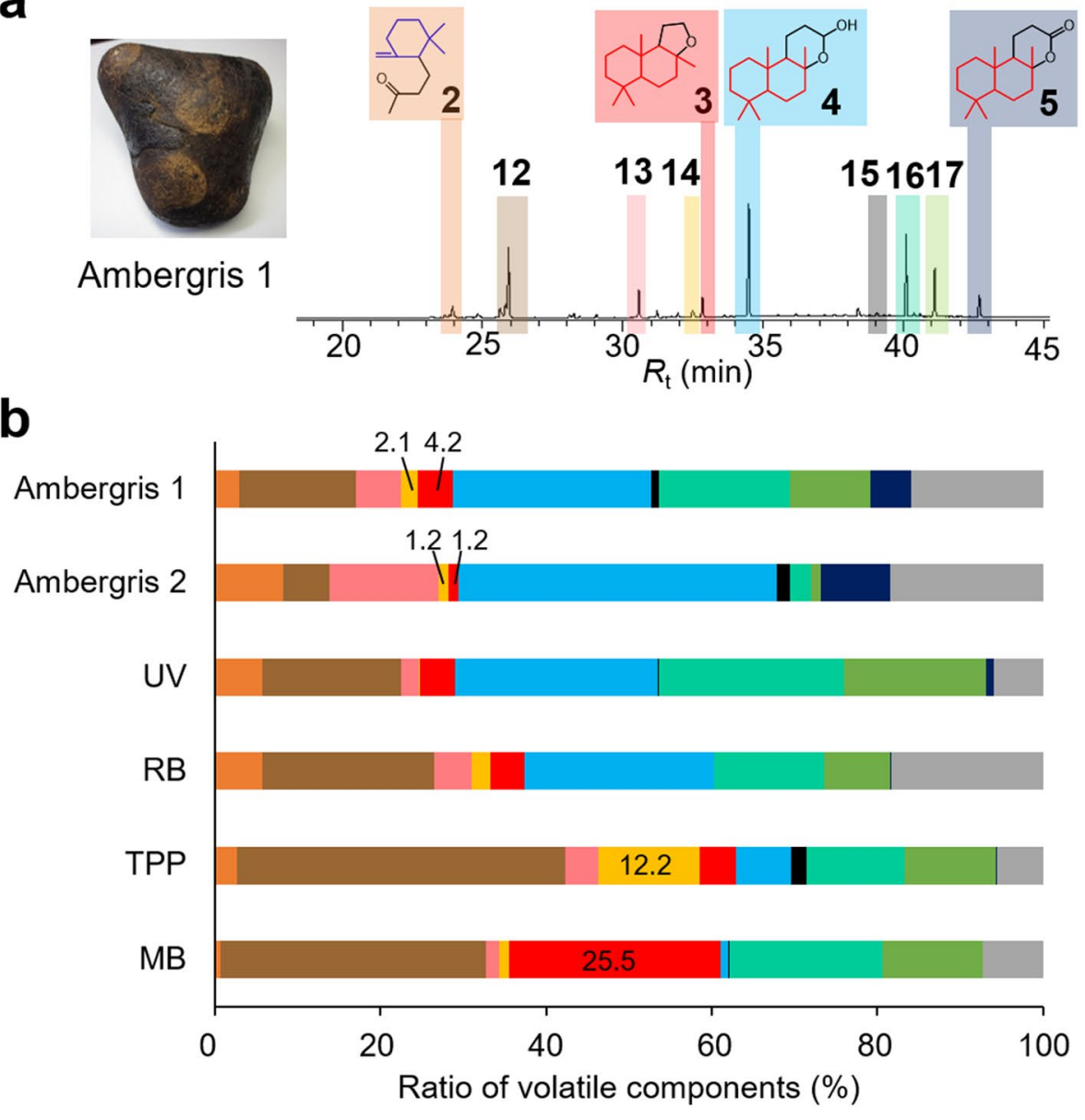

$\square=12 \square 13 \square 14 \square 3 \square 4 \square 15 \square 16 \square 17 \square 5 \square$ Others

C

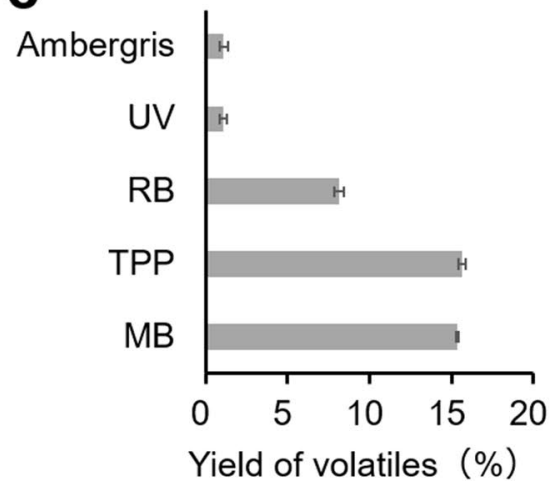

d

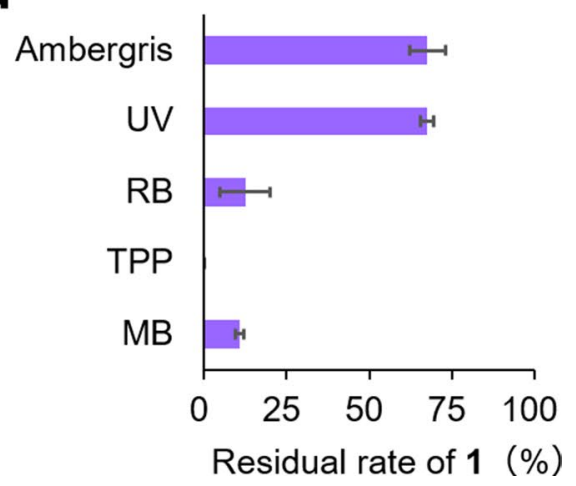

Figure 7. Conversion of $\mathbf{1}$ into volatile components. (a) GC-MS chromatogram of ambergris volatiles. Compounds 2-5 were identified, while compounds 12-17 were not. (b) Percentage of ambergris volatile components and volatile compounds produced by treating 1 with UV light and a photosensitizer (RB, TPP, or MB). The ratio of "others" was calculated using the total amount of compounds, except 2-5 and 12-17. (c) Yield of ambergris volatile components and volatile compounds produced by treatment of $\mathbf{1}$ with UV light and a photosensitizer (RB, TPP, or MB). (d) Residual rate of $\mathbf{1}$ in ambergris and reaction solution exposed to UV light and photosensitizer (RB, TPP, or MB).

Although earlier studies on the photooxidation of 1 were aimed at mimicking the production of volatile components of natural ambergris and isolating the volatiles ${ }^{9-11}$, none of the studies aimed to achieve the efficient 


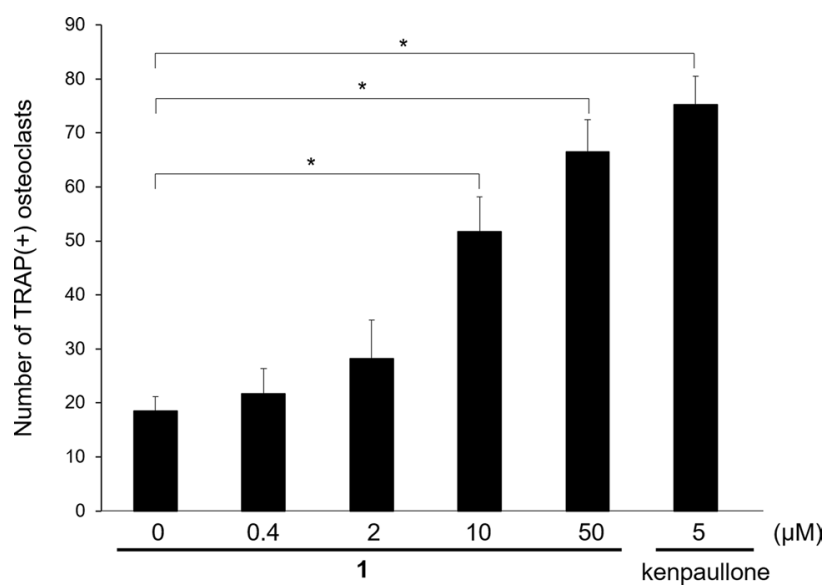

Figure 8. Biological effect of $\mathbf{1}$ on the osteoclast differentiation. The number of TRAP-positive osteoclasts, differentiated from RAW264.7 cells, was counted in the absence or presence of different concentrations of 1 . Kenpaullone is a positive control. The data are expressed as mean \pm S.D. $\left(n=3,{ }^{*}=P<0.01\right)$.

conversion of 1 to volatiles. In this study, we were able to obtain a yield of $8-15 \%$ (Fig. 7c), which was higher than the yields obtained previously for different purposes ${ }^{9-11}$ and the content in the natural ambergris analyzed by us (Fig. 7c). The synthetic system of volatiles constructed by us could change odor depending on the type of photosensitizers used (Fig. 7b). In the future, a variety of odors may be created by examining various reaction conditions including use of different photosensitizers. In addition, although unknown volatile compounds 12-17 were detected in this study (Fig. 7a and Supplementary Fig. 12), their structures could not be determined. New odor compounds may be identified in the future if a large amount of $\mathbf{1}$ is photooxidized. Further, we identified two biological activities of $\mathbf{1}$ : promotion of osteoclast differentiation and prevention of $A \beta$ neurotoxicity (Figs. 8 and 9). However, it remains unclear how this compound performs these activities. Identification of an intracellular target molecule of $\mathbf{1}$ may allow the discovery of therapeutic agents for osteopetrosis and Alzheimer's disease in the future.

This study differed from the conventional biosynthesis studies that have aimed to reconstruct natural biosynthetic pathways. It was a challenge to synthesize a rare natural product (1) whose biosynthetic pathway remains unclear, with an artificial biosynthetic route using an enzyme created in the laboratory. Many new natural products have been discovered by genome mining. However, if the biosynthetic enzyme is of a new type or if the natural producer of the product is unknown, genome mining cannot be performed. Therefore, it will be important in the future to synthesize desired compounds by artificially creating new biosynthetic enzymes. In addition, the system constructed in this study can be synthesize $\mathbf{1}$ analogues and fragrance analogues by redesigning enzymes and using substrate analogues, and will lead to the creation of compounds with numerous odors and biological activities beyond those found in nature in the future.

\section{Methods}

General. E. coli JM109 (Takara, Shiga, Japan) was used for sequencing analysis, and E. coli BL21(DE3) (Takara), pColdTF (Takara), and pColdI (Takara) were used to express BmeTC ${ }^{\mathrm{X}}$ genes. NMR spectra were recorded using a Bruker DPX 400 spectrometer (Billerica, MA, USA) at $400 \mathrm{MHz}$ for protons $\left({ }^{1} \mathrm{H}\right.$ ) and $100 \mathrm{MHz}$ for carbon $\left({ }^{13} \mathrm{C}\right)$. GC-MS was performed on a JMS-T100GCV spectrometer (JEOL, Tokyo, Japan) equipped with a DB- 1 capillary column $(30 \mathrm{~m} \times 0.25 \mathrm{~mm} \times 0.25 \mu \mathrm{m}$; J\&W Scientific. Inc., Folsom, CA, USA), using the EI mode operated at $70 \mathrm{eV}$. GC analyses were performed using a Shimadzu GC-2014 chromatograph equipped with a flame ionization detector and using a DB-1 capillary column $(30 \mathrm{~m} \times 0.25 \mathrm{~mm} \times 0.25 \mu \mathrm{m}$; J\&W Scientific, Inc.). $\mathrm{GC}$ and GC-MS conditions for the $\mathrm{BmeTC}^{\mathrm{X}}$ products were as follows: injection temperature $=300^{\circ} \mathrm{C}$, column temperature $=220-300^{\circ} \mathrm{C}\left(1^{\circ} \mathrm{C} \mathrm{min}{ }^{-1}\right)$. GC and GC-MS conditions for the volatile compounds were as follows: injection temperature $=200^{\circ} \mathrm{C}$, column temperature $=40-300{ }^{\circ} \mathrm{C}\left(5^{\circ} \mathrm{C} \mathrm{min}{ }^{-1}\right)$ for $\mathrm{GC}$ and $30-300{ }^{\circ} \mathrm{C}\left(5^{\circ} \mathrm{C} \mathrm{min}-\right.$ $\left.{ }^{1}\right)$ for GC-MS. Compound 6 was purchased from Wako Pure Chemical Industries, Ltd. (Osaka, Japan). Two ambergris samples (NSMT M55020 and NSMT M55019; Supplementary Fig. 7) stored in the National Museum of Nature and Science (Japan) for more than 30 years were used for the analysis of volatile components.

Isolation and structural analysis of $1,7,10$, and 11 synthesized from substrate 6 by BmeTC $^{X}$. Compound 11, biosynthesized in the yeast $P$. pastoris, was identified previously by MS analysis ${ }^{17}$. However, no NMR data were available for 11. Therefore, isolation and structural analysis of 11 was performed in the present study. Compounds 1, 7, and $\mathbf{1 0}$ were isolated for use as substrates for enzymatic reactions and material for conversion into volatile components. As a typical example, the method used to isolate 1, 7, 10, and 11 produced by BmeTC $\mathrm{D}^{\mathrm{D} 373 \mathrm{C} / \mathrm{L} 596 \mathrm{~A}}$ is described below. Compounds 1, 7, and 10 were synthesized and isolated via a method similar to BmeTC ${ }^{\mathrm{D} 373 \mathrm{C} / \mathrm{L} 596 \mathrm{~A}}$, mainly using BmeTC ${ }^{\mathrm{Y} 167 \mathrm{~A} / \mathrm{D} 373 \mathrm{C}}, \mathrm{BmeTC}^{\mathrm{WT}}$, and $\mathrm{BmeTC}^{\mathrm{D} 373 \mathrm{C}}$, respectively. 
a

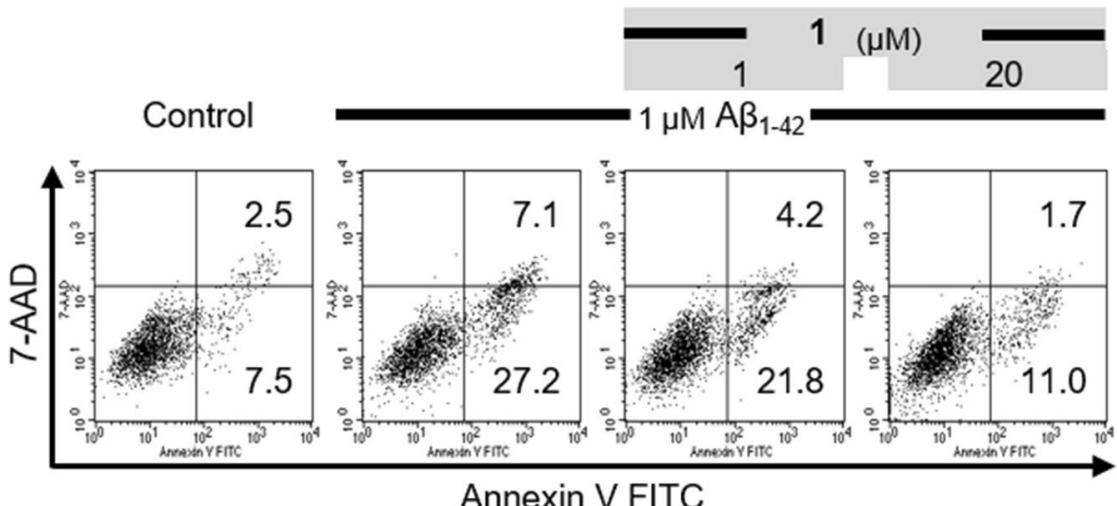

b

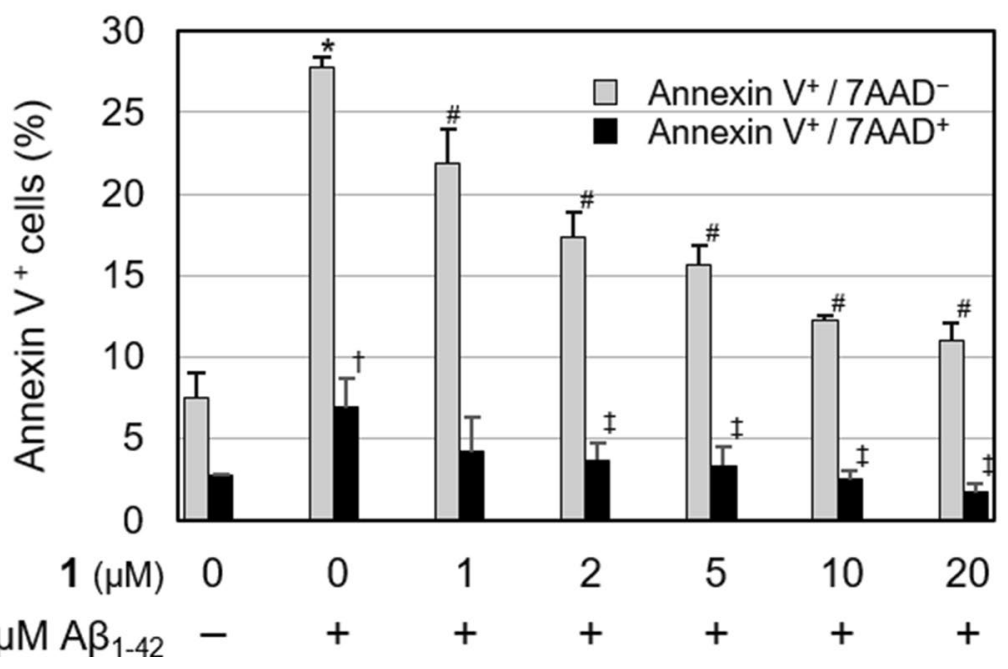

Figure 9. Protective effect of 1 on $A \beta_{1-42}$-induced apoptosis in SK-N-SH cells. Cells were pretreated with different concentrations of $\mathbf{1}(1,2,5,10$ and $20 \mu \mathrm{M})$ for $24 \mathrm{~h}$ before being exposed to $1 \mu \mathrm{M}$ A $\beta_{1-42}$ for $24 \mathrm{~h}$. Apoptotic cells were analyzed via flow cytometry using an Annexin V/7-AAD staining assay. (a) Dot plots of representative experiments. The number in the lower right quadrant signifies the percentage of early apoptotic cells (Annexin $\mathrm{V}^{+} / 7-\mathrm{AAD}^{-}$), and the upper right quadrant signifies the percentage of late apoptotic and dead (Annexin $\mathrm{V}^{+} / 7-\mathrm{AAD}^{+}$) cells. (b) Percentages of early apoptotic cells (Annexin $\mathrm{V}^{+} / 7-\mathrm{AAD}^{-}$) and late apoptotic and dead cells $\left(\right.$ Annexin $\left.\mathrm{V}^{+} / 7-\mathrm{AAD}^{+}\right)$. Data are expressed as mean $\pm \mathrm{SEM} ;(\mathrm{n}=3){ }^{*}{ }^{*}$ and ${ }^{\dagger}$ refer to the comparison of $A \beta_{1-42}$ alone group versus control group in Annexin $\mathrm{V}^{+} / 7-\mathrm{AAD}^{-}$and Annexin $\mathrm{V}^{+} / 7-\mathrm{AAD}^{+}$cells, respectively; ${ }^{*}$ or $^{\dagger}=\mathrm{P}<0.01 .{ }^{*}$ and ${ }^{*}$ refer to the comparison of 1 pretreatment groups versus $\mathrm{A} \beta_{1-42}$ alone group in Annexin $\mathrm{V}^{+} / 7-\mathrm{AAD}^{-}$and Annexin $\mathrm{V}^{+} / 7-\mathrm{AAD}^{+}$cells, respectively; ${ }^{*}$ or ${ }^{\ddagger}=\mathrm{P}<0.01$.

The expression and preparation of the a cell-free extract was basically the same as in Ref. 20 as described below. E. coli BL21(DE3) harboring pColdTF-BmeTC ${ }^{\text {D373C/L596A }}$ was grown at $37^{\circ} \mathrm{C}$ in LB medium $(1 \mathrm{~L})$ with $100 \mu \mathrm{g} \mathrm{mL} \mathrm{m}^{-1}$ ampicillin ${ }^{20}$. Expression of the recombinant protein was induced by adding $0.1 \mathrm{mM}$ IPTG when $\mathrm{OD}_{600}$ reached $\sim 0.6^{20}$. Further cultivation of BL21(DE3) recombinants was performed for $24 \mathrm{~h}$ at $15^{\circ} \mathrm{C}^{20}$. E. coli cells expressing recombinant $\mathrm{BmeTC}^{\mathrm{D} 373 \mathrm{C} / \mathrm{L} 596 \mathrm{~A}}$ were harvested by centrifugation and resuspended in buffer $\mathrm{A}$ $(15 \mathrm{~mL} / 5 \mathrm{~g})$ containing $50 \mathrm{mM}$ Tris- $\mathrm{HCl}$ (pH 7.5), $2.5 \mathrm{mM}$ dithiothreitol, $1 \mathrm{mM}$ EDTA, $0.1 \%$ ascorbic acid and $0.1 \%$ Tween- $80^{20}$. Cells were disrupted by sonication with UP200s (Hielscher Ultrasonics $\mathrm{GmbH}$ ) at $4-10^{\circ} \mathrm{C}$ for $15 \mathrm{~min}^{20}$. The resulting suspension was centrifuged at $12,300 \times \mathrm{g}$ for $20 \mathrm{~min}$ (twice) ${ }^{20}$. The pellet was discarded, and the resulting supernatant was used as the cell-free extract.

To isolate product 11 formed by BmeTC ${ }^{\mathrm{D} 373 \mathrm{C} / \mathrm{L} 596 \mathrm{~A}}, \mathbf{6}(7.5 \mathrm{mg})$ was emulsified with Tween $80(150 \mathrm{mg})$ in buffer A $(75 \mathrm{~mL})$, and incubated with the cell-free extract $(300 \mathrm{~mL})$ at $30^{\circ} \mathrm{C}$ for $112 \mathrm{~h}$. Subsequently, $15 \% \mathrm{KOH} / \mathrm{MeOH}$ solution $(450 \mathrm{~mL})$ was added to the reaction mixture and lipophilic products were extracted with $n$-hexane $(400 \mathrm{~mL} \times 3)$ and concentrated. The gas chromatogram of $n$-hexane extract is shown (Supplementary Fig. 14). The $n$-hexane extract $(5.29 \mathrm{~g})$ was partially purified using silica gel $(250 \mathrm{~g})$ column chromatography with $n$-hexane and $n$-hexane/EtOAc (100:20). The fraction (Fra. A: $5.0 \mathrm{mg}$ ) eluted with $n$-hexane contained substrates 6, 8, 10, and 11, whereas the fraction (Fra. B: $188.0 \mathrm{mg}$ ) eluted with $n$-hexane/EtOAc (100:20) contained 1, 7, and 9. Pure 11 (oil; $1.5 \mathrm{mg}$ ) and 10 (oil; $0.1 \mathrm{mg}$ ) were obtained by $\mathrm{SiO}_{2} \mathrm{HPLC}$ (Inertsil 100A, 7.6×250 mm; GL Science) with $n$-hexane from Fra. A, and pure $\mathbf{1}$ (oil; $2.1 \mathrm{mg}$ ) and 7 (oil; $0.6 \mathrm{mg}$ ) were obtained by $\mathrm{SiO}_{2} \mathrm{HPLC}$ (Inertsil 100A, $7.6 \times 250 \mathrm{~mm}$; GL Science) with $n$-hexane:THF (100:2) from Fra. B. 
The structure of compound 11 was determined using MS (Supplementary Fig. 15) and NMR (Supplementary Figs. 16-21). HR-EI-MS detected $m / z 410.3904[\mathrm{M}]^{+}$(calculated 410.3913 for $\mathrm{C}_{30} \mathrm{H}_{50}$ ). The structures and purity (>99\%) of $\mathbf{1}, \mathbf{7}$, and $\mathbf{1 0}$ were confirmed by ${ }^{1} \mathrm{H}$ NMR to be consistent with those of previous reports ${ }^{15,27,28}$.

Analysis of BmeTC ${ }^{X}$ products using a cell-free system. Construction of pColdTF-BmeTCWT and pColdTF-BmeTC ${ }^{\mathrm{Y} 167 \mathrm{~A}}$ has been previously reported ${ }^{20,28}$. Site-directed mutagenesis of pColdTF-BmeTC ${ }^{\mathrm{WT}}$ and pColdTF-BmeTC ${ }^{\mathrm{D} 373 \mathrm{C}}$ was performed using the Quik Change Site-directed Mutagenesis Kit (Agilent Technologies, Santa Clara, CA, USA) and primers which are listed in Supplementary Table 2. The pColdTF-BmeT$\mathrm{C}^{\mathrm{Y} 257 \mathrm{~A}}$ was synthesized by Genewiz (Morrisville, NC, USA) using codon-optimized sequences for E. coli. E. coli BL21(DE3) harboring pColdTF-BmeTC ${ }^{\mathrm{X}}$ (X: WT, D373C/A/F/G/H/L/M/N/Q/S/W, Y167A, Y255A, Y257A, $\mathrm{N} 302 \mathrm{~A}, \mathrm{~L} 596 \mathrm{~A}$ and $\mathrm{F} 600 \mathrm{~A}$ ) was grown at $37^{\circ} \mathrm{C}$ in LB medium (1 L) with $100 \mu \mathrm{g} \mathrm{mL}{ }^{-1}$ ampicillin. The expression and preparation of the a cell-free extract was basically the same as in Ref. 20 as described below. Expression of the recombinant protein was induced by adding $0.1 \mathrm{mM}$ IPTG when $\mathrm{OD}_{600}$ reached $\sim 0.6$. BL21(DE3) recombinants were further cultured for $24 \mathrm{~h}$ at $15^{\circ} \mathrm{C}^{20}$. E. coli cells expressing recombinant BmeTC $\mathrm{C}^{\mathrm{X}}$ were harvested by centrifugation and resuspended in buffer A ( $3 \mathrm{~mL} / \mathrm{g}$ cells) containing $50 \mathrm{mM}$ Tris- $\mathrm{HCl}$ ( $\mathrm{pH} 7.5), 2.5 \mathrm{mM}$ dithiothreitol, $1 \mathrm{mM}$ EDTA, $0.1 \%$ ascorbic acid and $0.1 \%$ Tween $-80^{20}$. Cells were disrupted via sonication using an UP200s (Hielscher Ultrasonics $\mathrm{GmbH}$ ) at $4-10{ }^{\circ} \mathrm{C}$ for $15 \mathrm{~min}^{20}$. The resulting suspension was centrifuged at $12,300 \times g$ for $20 \mathrm{~min}$ (twice) ${ }^{20}$. The pellet was discarded, and the resulting supernatant was used as cell-free extracts. Sodium dodecyl sulfate polyacrylamide gel electrophoresis (SDS-PAGE) using 10\% gel confirmed that all cell-free extracts contained approximately the same amount of BmeTC ${ }^{\mathrm{X}}$ (Supplementary Fig. 1).

To analyze BmeTC ${ }^{X}$ products, the substrate $(6,7$, or 10; $0.1 \mathrm{mg})$ was emulsified with Tween $80(20 \mathrm{mg})$ in buffer $\mathrm{A}(1 \mathrm{~mL})$, and incubated with the cell-free extracts containing BmeTC ${ }^{\mathrm{X}}(4 \mathrm{~mL})$ at $37^{\circ} \mathrm{C}$ for $64 \mathrm{~h}$. After $15 \% \mathrm{KOH} / \mathrm{MeOH}$ solution $(6 \mathrm{~mL})$ was added to the reaction mixture, the lipophilic products were extracted with $n$-hexane $(10 \mathrm{~mL} \times 3)$ and concentrated. Next, the $n$-hexane extract containing the products and residual substrate was analyzed by GC and GC-MS. Standard deviations were calculated from the results of 3 replicates.

Analysis of $\mathrm{BmeTC}^{X}$ products using purified enzymes. In order to analyze the correct enzyme activity, BmeTC ${ }^{\mathrm{X}}$ (X: WT, D373C, Y167A/D373C, Y257A/D373C, N302A/D373C and D373C/L596A) was expressed without the fused TF-tag. The BmeTC ${ }^{\mathrm{WT}}$ gene was excised from the NdeI and XhoI sites of pColdTF-BmeTC ${ }^{\mathrm{WT}}$, and introduced into the same site of pColdI to construct pColdI-BmeTC ${ }^{\mathrm{WT}}$. Next, pColdI-BmeTC ${ }^{\mathrm{D} 33 \mathrm{C}}$ and pColdI-BmeTC ${ }^{\mathrm{Y} 167 \mathrm{~A} / \mathrm{D} 373 \mathrm{C}}$ were synthesized by Genewiz (Morrisville, NC, USA) using codon-optimized sequences for E. coli, following which pColdI-BmeTC ${ }^{\mathrm{Y} 257 \mathrm{~A} / \mathrm{D} 373 \mathrm{C}}$ and pColdI-BmeTC ${ }^{\mathrm{N} 302 \mathrm{~A} / \mathrm{D} 373 \mathrm{C}}$ were prepared via a Quik Change Site-directed Mutagenesis Kit (Stratagene) using pColdI-BmeTC ${ }^{\mathrm{D} 373 \mathrm{C}}$ as a template and the primers listed in Supplementary Table 3. Then pColdI-BmeTC ${ }^{\mathrm{x}}$ was introduced into BL21(DE3) together with pGro7, and soluble BmeTC ${ }^{\mathrm{X}}$ was expressed. The expression and purification of $\mathrm{BmeTC}^{\mathrm{X}}$ was basically the same as in Ref. 29 as described below. After culturing as in the case of pColdTF-BmeTC ${ }^{\mathrm{WT}}$, cells expressing the recombinant protein were harvested by centrifugation and disrupted by sonication in buffer $\mathrm{B}[20 \mathrm{mM}$ Tris- $\mathrm{HCl}(\mathrm{pH}$ 7.9) and $300 \mathrm{mM} \mathrm{NaCl}$ ] (30 mL/L cultured cells) containing $10 \mathrm{mM}$ imidazole and $0.1 \%$ Tween 80 at $4{ }^{\circ} \mathrm{C}^{29}$. The homogenate was centrifuged at $18,270 \times g$ for $20 \mathrm{~min}$ to prepare the supernatant containing soluble Histagged fusion protein, which was loaded into a Ni-NTA agarose column (0.2 mL; Qiagen, Hilden, Germany), followed by washing with $10 \mathrm{~mL}$ of buffer B containing $10 \mathrm{mM}$ imidazole and then by $12 \mathrm{~mL}$ of buffer B containing $50 \mathrm{mM}$ imidazole and $0.1 \%$ Tween $80^{29}$. The purified protein was eluted with $3 \mathrm{~mL}$ buffer B containing $250 \mathrm{mM}$ imidazole and $0.1 \%$ Tween 80 , and buffer-exchanged into $3 \mathrm{~mL}$ buffer $\mathrm{C}$ [ $50 \mathrm{mM}$ Tris- $\mathrm{HCl}(\mathrm{pH} 7.5)$, $2.5 \mathrm{mM}$ dithiothreitol, $1 \mathrm{mM}$ EDTA, $300 \mathrm{mM} \mathrm{NaCl}$ and $0.1 \%$ Tween-80] by gel-filtration chromatography using a Sephadex G-10 column (GE Healthcare, Pittsburgh, PA, USA) ${ }^{29}$. The expression and purification of BmeTC ${ }^{\mathrm{X}}$ were analyzed via 10\% SDS-PAGE (Supplementary Fig. 5).

The reaction mixture used to analyze the $\mathrm{BmeTC}^{\mathrm{X}}$ products in buffer $\mathrm{C}$ (total volume: $1 \mathrm{~mL}$ ) contained $8.2 \mathrm{mM}(50 \mu \mathrm{g})$ substrate $\left(6,7\right.$ or 10) emulsified with $1 \mathrm{mg}$ Tween 80 and $1.4 \mu \mathrm{M}(50 \mu \mathrm{g})$ purified BmeTC $^{\mathrm{X}}$. Reactions were performed at $37^{\circ} \mathrm{C}$ for $64 \mathrm{~h}$. As shown in the representative example in Supplementary Fig. 22, the time-dependent activities of $\mathrm{BmeTC}^{\mathrm{X}}$ were linear at $64 \mathrm{~h}$. After $15 \% \mathrm{KOH} / \mathrm{MeOH}$ solution $(1.2 \mathrm{~mL}) \mathrm{was}$ added to the reaction mixture, the lipophilic products were extracted using $n$-hexane $(2 \mathrm{~mL} \times 3)$ and the products and the residual substrate was analyzed using GC and GC-MS. Standard deviations were calculated from the results of 3 replicates.

Conversion of 1 into volatile components. Two ambergris tinctures were prepared with $1 \mathrm{mg}$ ambergris/ $200 \mu \mathrm{L}(95 \% \mathrm{EtOH})$. UV treatment of 1 was performed by irradiating a sample [1 $\mathrm{mg} \mathbf{1} / 200 \mu \mathrm{L}(95 \%$ $\mathrm{EtOH})]$ in a glass vial with a UV lamp $(15 \mathrm{~W})$ at $26^{\circ} \mathrm{C}$ for 6 weeks. Visible light treatment of 1 using a photosensitizer was carried out by irradiating a sample [ $1 \mathrm{mg}$ 1/200 $\mu \mathrm{L}$ (RB and MB: 95\% EtOH; TPP: dichloromethane)] in a glass vial with LED visible light lamp $(60 \mathrm{~W})$ at $26^{\circ} \mathrm{C}$ for $4 \mathrm{~h}$, followed by adding the photosensitizer (RB and MB: $100 \mu \mathrm{M}$; TPP: $50 \mu \mathrm{M}$ ) every hour and stirring. The samples were directly injected for analysis of volatile compounds by GC and GC-MS. The compounds $\mathbf{2 - 5}$ were identified by comparing the EIMS spectra of 2-5 with those of the NIST library (Supplementary Figs. 8-11). Quantification of volatile compounds by GC was performed by comparison with the peak area of authentic 3 (Kao, Tokyo, Japan). Standard deviations were calculated from the results of 3 replicates.

Cell culture and treatments. Murine pre-osteoblastic MC3T3-E1 cells (RIKEN Cell Bank, Tsukuba, Japan) were cultured in Minimum Essential Medium Eagle-alpha modification (a-MEM) supplemented with $10 \%$ fetal bovine serum (FBS), $100 \mu \mathrm{g} / \mathrm{mL}$ streptomycin, and $100 \mathrm{U} / \mathrm{mL}$ penicillin. For induction of osteoblastic 
differentiation, the cells were incubated in $\alpha$-MEM complete medium supplemented with $10 \mathrm{mM} \beta$-glycerol phosphate, $50 \mu \mathrm{g} / \mathrm{mL}$ ascorbic acid, $10 \mathrm{nM}$ dexamethasone, and $10 \mu \mathrm{M} 1$ or $0.1 \%$ DMSO as a control; the medium was exchanged with fresh medium every $3 \mathrm{~d}$. Murine macrophage-like pre-osteoclastic RAW264.7 cells (ATCC, Manassas, VA, USA) were cultured in a-MEM medium supplemented with 10\% FBS, 2 mM L-glutamine, 100 U/ $\mathrm{mL}$ penicillin, and $100 \mu \mathrm{g} / \mathrm{mL}$ streptomycin. In order to induce osteoclastic differentiation, $100 \mathrm{ng} / \mathrm{mL}$ sRANKL (Oriental Yeast, Japan) was added to the medium with different concentrations of 1 or $0.1 \%$ DMSO as a control and incubated for $4 \mathrm{~d}$ with $5 \% \mathrm{CO}_{2}$ at $37^{\circ} \mathrm{C}$. Human neuroblastoma SK-N-SH cells were obtained from Cell Resource Center for Biomedical Research, Institute of Development, Aging and Cancer, Tohoku University (Sendai, Japan) and cultured in DMEM supplemented with 10\% FBS, 1 mM sodium pyruvate and 1\% penicillin/ streptomycin. SK-N-SH cells were seeded at a density of $1 \times 10^{6}$ cells $/ \mathrm{mL}$, and following overnight incubation, treated with or without $1(1-20 \mu \mathrm{M})$ for $24 \mathrm{~h}$. Subsequently, culture supernatants containing 1 were removed, and the cells were exposed to $1 \mu \mathrm{M} \mathrm{A} \beta_{1-42}$ (Wako, Osaka, Japan) for an additional $24 \mathrm{~h}$ to induce Amyloid $\beta$ $(\mathrm{A} \beta)$-mediated neurotoxicity.

Alizarin red S staining. MC3T3-E1 cells cultured in the osteoblastic differentiation medium for 3 weeks and were subsequently fixed with $4 \%$ PFA for $30 \mathrm{~min}$ at $24^{\circ} \mathrm{C}$. Finally, cells were incubated for $45 \mathrm{~min}$ at $24^{\circ} \mathrm{C}$ with $1 \%$ alizarin red S (FUJIFILM Wako Pure Chemical Corp., Osaka, Japan), and then washed by distilled water $^{30}$.

TRAP staining. Matured osteoclasts were fixed with $10 \%$ glutaraldehyde for 15 min at $37{ }^{\circ} \mathrm{C}$ and subsequently incubated for $10 \mathrm{~min}$ at $37^{\circ} \mathrm{C}$ in TRAP staining buffer containing $10 \mathrm{mg} / \mathrm{mL}$ naphthol AS-MX phosphate, $0.3 \mathrm{mg} / \mathrm{mL}$ Fast Red Violet LB Salt, $0.1 \mathrm{M}$ sodium acetate, $0.3 \mathrm{M}$ potassium tartrate, $0.1 \%$ Triton X-100, and $0.1 \mathrm{M}$ acetic acid $^{31}$. TRAP-positive osteoclasts with more than 3 nuclei were considered as mature osteoclasts and counted using a light microscope (Olympus IX73, Tokyo, Japan).

Apoptosis assay by flow cytometry. For the apoptosis assay, flow cytometric analysis was performed using FITC-Annexin V (Biolegend, San Diego, CA, USA) and 7-Amino-Actinomycin (7-AAD; Biolegend). Cells were pretreated with or without 1 for $24 \mathrm{~h}$, followed by $24 \mathrm{~h}$ exposure to $1 \mu \mathrm{M} \mathrm{A} \beta_{1-42}$. Subsequently, cells were harvested, washed twice with phosphate-buffered saline containing $0.1 \%$ bovine serum albumin, and resuspended in Annexin V binding buffer at $1 \times 10^{6}$ cells $/ \mathrm{mL}$. Thereafter, cells were stained with FITC-Annexin V $(5 \mu \mathrm{g} / \mathrm{mL})$ and 7 -AAD $(0.5 \mu \mathrm{g} / \mathrm{mL})$ for $15 \mathrm{~min}$ in the dark. Finally, cells were analyzed using FACSCalibur flow cytometry system (BD Bioscience, San Jose, CA, USA). A minimum of 10,000 events was collected and the percentage of apoptotic cells was calculated using the CellQuest software (BD Bioscience).

Statistical analysis. Statistical significance was determined by one-way analysis of variance followed by the Tukey-Kramer test for multiple comparisons at $\mathrm{P}<0.01$.

\section{Data availability}

Data supporting the findings of this study are available within the article and the Supplementary Information files, and from the corresponding author upon reasonable request.

Received: 27 July 2020; Accepted: 29 October 2020

Published online: 12 November 2020

\section{References}

1. Clarke, R. The origin of ambergris. LAJAM 5, 7-21 (2006).

2. Schaefer B. Natural Products in the Chemical Industry. 140-168 (Springer, Berlin, 2014)

3. Ohloff, G. Fragrance Chemistry (ed. Theimer, E. T.) 535-573 (Academic Press, New York, 1982).

4. Mahdihassan, S. Bazar Drugs and Folk Medicine in Pakistan 1st edn. (Hamdard Foundation, Karachi, Pakistan, 1984).

5. Taha, S. A. Studies on the mode of action of ambrein as a new antinociceptive compound. Jpn. J. Pharmacol. 60, 67-71 (1992).

6. Taha, S. A., Islam, M. W. \& Ageel, A. M. Effect of ambrein, a major constituent of ambergris, on masculine sexual behavior in rats. Arch. Int. Pharmacodyn. Ther. 329, 283-294 (1995).

7. Melnyk, J. P. \& Marcone, M. F. Aphrodisiacs from plant and animal sources-a review of current scientific literature. Food Res. Int. 44, 840-850 (2011).

8. Rowland, S. J., Sutton, P. A. \& Knowles, T. D. J. The age of ambergris. Nat. Prod. Res. 33, 3134-3142 (2019).

9. Ohloff, G., Schulte-Elte, K. H. \& Müller, B. L. Formation of ambergris odorants from ambrein under simulated natural conditions. Helv. Chim. Acta 60, 2763-2766 (1977).

10. Awano, K., Ishizaki, S., Takazawa, O. \& Kitahara, T. Analysis of ambergris tincture. Flavour Fragr. J. 20, 18-21 (2005).

11. Rowland, S. J., Payne, D. \& Sutton, P. A. Simulated environmental photo- and auto-oxidation of ambrein. EarthArXiv [pre print: https://doi.org/10.31223/osf.io/x8d4e] (2018).

12. Mori, K. \& Tamura, H. Triterpenoid total synthesis I. Synthesis of ambrein and Ambrox Liebigs. Ann. Chem. 1990, 361-368 (1990).

13. Tanimoto, H. \& Oritani, Y. Synthesis of (+)-ambrein. Tetrahedron 53, 3527-3536 (1997).

14. Fujiwara, N., Kinoshita, M. \& Akita, H. New total synthesis of (+)-ambrein. Tetrahedron Assymmetry. 17, 3037-3045 (2006).

15. Ueda, D., Hoshino, T. \& Sato, T. Cyclization of squalene from both termini: Identification of an onoceroid synthase and enzymatic synthesis of ambrein. J. Am. Chem. Soc. 135, 18335-18338 (2013).

16. Sato, T., Okuno, K., Takehana, T. \& Koike, S. WO2017150695A1 (2017).

17. Moser, S. et al. Whole-cell (+)-ambrein production in the yeast Pichia pastoris. Metab. Eng. Commun. 7, e00077 (2018).

18. Moser, S., Leitner, E., Plocek, T. J., Vanhessche, K. \& Pichler, H. Engineering of Saccharomyces cerevisiae for the production of (+)-ambrein. Yeast 37, 163-172 (2020). 
19. Ke, D., Caiyin, Q., Zhao, F., Liu, T. \& Lu, W. Heterologous biosynthesis of triterpenoid ambrein in engineered Escherichia coli. Biotechnol Lett. 40, 399-404 (2018).

20. Tenkovskaia, L., Murakami, M., Okuno, K., Ueda, D. \& Sato, T. Analysis of the catalytic mechanism of bifunctional triterpene/ sesquarterpene cyclase: Tyr167 functions to terminate cyclization of squalene at the bicyclic step. ChemBioChem 18, 1910-1913 (2017).

21. Shen, Y. C. et al. Chemical transformation and biological activities of ambrein, a major product of ambergris from Physeter macrocephalus (sperm whale). J. Nat. Prod. 70, 147-153 (2007).

22. Akiba, Y. et al. The inhibitors of cyclin-dependent kinases and GSK-3 $\beta$ enhance osteoclastogenesis. Biochem. Biophys. Rep. 5, 253-258 (2015).

23. Hardy, J. \& Selkoe, D. J. The amyloid hypothesis of Alzheimer's disease: progress and problems on the road to therapeutics. Science 297, 353-356 (2002)

24. Rowland, S. J., Sutton, P. A. \& Wolff, G. A. Biosynthesis of ambrein in ambergris: evidence from isotopic data and identification of possible intermediates. Nat. Prod. Res. 30, 1-7 (2019).

25. Saga, Y. et al. Identification of serratane synthase gene from the fern Lycopodium clavatum. Org. Lett. 19, 496-499 (2017).

26. Otani, Y., Maoka, T., Kawai-Noma, S., Saito, K. \& Umeno, D. Construction of a pathway to C50-₹-carotene. PLoS ONE 14, e0216729 (2019).

27. Sato, T. \& Hoshino, T. Functional analysis of the DXDDTA motif in squalene-hopene cyclase by site-directed mutagenesis experiments: initiation site of the polycyclization reaction and stabilization site of the carbocation intermediate of the initially cyclized A-ring. Biosci. Biotechnol. Biochem. 63, 2189-2198 (1999).

28. Sato, T., Hoshino, H., Yoshida, S., Nakajima, M. \& Hoshino, T. Bifunctional triterpene/sesquarterpene cyclase: tetraprenyl- $\beta$ curcumene cyclase is also squalene cyclase in Bacillus megaterium. J. Am. Chem. Soc. 133, 17540-17543 (2011).

29. Abe, T., Ozaki, S., Ueda, D. \& Sato, T. Insight into isoprenoid biosynthesis by functional analysis of isoprenyl diphosphate synthases from Mycobacterium vanbaalenii and Mycobacterium tuberculosis. ChemBioChem 21, 2931-2938 (2020).

30. Fu, C., Yang, X., Tan, S. \& Song, L. Enhancing cell proliferation and osteogenic differentiation of MC3T3-E1 pre-osteoblasts by BMP-2 delivery in graphene oxide-incorporated PLGA/HA biodegradable microcarriers. Sci. Rep. 7, 12549 (2017).

31. Mediero, A., Ramkhelawon, B., Perez-Aso, M., Moore, K. J. \& Cronstein, B. N. Netrin-1 is a critical autocrine/paracrine factor for osteoclast differentiation. J. Bone Miner. Res. 30, 837-854 (2015).

\section{Acknowledgements}

This work was supported in part by the JSPS KAKENHI (Grant\# 19K23663 to DU, and 18H02145, 19K22273, and 19H04648 to TS) and Niigata University Interdisciplinary Research (U-go) Grant to TS. The authors thank Dr. Toshihiko Takehana (ADEKA Corporation) for the kind gifts of some amount of $\mathbf{1}$, which was produced and isolated by the methods constructed in this study. We would like to thank Editage for English language editing.

\section{Author contributions}

Yo.K., T.H., and T.S. designed the project and wrote the manuscript. Y.Y., K.O., M.I., K.C., D.U., and T.S. performed the analysis of enzymes. Yu.K., Y.T., T.K.Y., and T.S. conducted the analysis of volatiles. Yo.K. performed the experiments of bone cells. H.T. performed the experiments of apoptotic cells. Y.Y., Yu.K., K.O., M.I., K.C., D.U., Y.T., T.K.Y., Yo.K., T.H., and T.S. analyzed the data.

\section{Competing interests}

The authors declare no competing interests.

\section{Additional information}

Supplementary information is available for this paper at https://doi.org/10.1038/s41598-020-76624-y.

Correspondence and requests for materials should be addressed to Y.K., T.H. or T.S.

Reprints and permissions information is available at www.nature.com/reprints.

Publisher's note Springer Nature remains neutral with regard to jurisdictional claims in published maps and institutional affiliations.

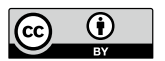

Open Access This article is licensed under a Creative Commons Attribution 4.0 International License, which permits use, sharing, adaptation, distribution and reproduction in any medium or format, as long as you give appropriate credit to the original author(s) and the source, provide a link to the Creative Commons licence, and indicate if changes were made. The images or other third party material in this article are included in the article's Creative Commons licence, unless indicated otherwise in a credit line to the material. If material is not included in the article's Creative Commons licence and your intended use is not permitted by statutory regulation or exceeds the permitted use, you will need to obtain permission directly from the copyright holder. To view a copy of this licence, visit http://creativecommons.org/licenses/by/4.0/.

(c) The Author(s) 2020 